\title{
The story of the "Qiulai" qin unraveled by radiocarbon dating, Chinese inscriptions and material characterization
}

\author{
Marie-Gabrielle Durier ${ }^{1,2,3^{*}} \mathbb{D}$, Alexandre Girard-Muscagorry ${ }^{3,4}$, Christine Hatté ${ }^{{ }^{*}}$, Tiphaine Fabris ${ }^{2,5}$, \\ Cyrille Foasso ${ }^{6}$, Witold Nowik ${ }^{2,5}$ and Stéphane Vaiedelich ${ }^{2,3}$
}

\begin{abstract}
An ancient table zither qin, an emblematic stringed instrument of traditional Chinese music, has been rediscovered in the museum collection of the Conservatoire National des Arts et Métiers (inv.4224, CNAM collection), Paris. This instrument named "Qiulai" gin, whose origin is poorly documented, can claim to be one of the oldest gin preserved in European collections; its state of conservation is exceptional. A thorough examination was carried out based on an innovative approach combining museum expertise, material characterization analyses (optical microscopy, VIS/ IR/UV imaging, X-ray fluorescence, SEM-EDS, Raman) and advanced radiocarbon dating technology (MICADAS). Our results highlight the great coherence with the traditional manufacturing practices mentioned in early Qing dynasty gin treatises and poems, in particular the collection of materials with highly symbolic meanings referring to the gin sound, nature and the universe. The reuse of resinous wood of the Taxus family from a building such as a temple has been demonstrated. The ash layer contains bone black, crushed malachite and residues of silica, ochres, potassium and magnesium aluminosilicates. Our study confirms the antiquity of the "Qiulai" qin in Europe by indicating that it was most likely made in the small [1659-1699] interval of about 30 years at the turn of the eighteenth century.
\end{abstract}

Keywords: gin, Chinese zither, Tang Kai, Musical instrument, eighteenth century, Radiocarbon dating, Spectroscopy, Qin dynasty texts

\section{Introduction and research aims}

The qin or guqin ("old qin") is a seven-stringed Chinese table zither regarded as one of the oldest chordophones in China. Based on surviving early written sources and archeological findings, the instrument is attested since the Zhou dynasty (eleventh-fifth century B.C.) and its definitive organological features were established during the Western Jin dynasty (265-316) [1]. Its construction appears simple but allows a wide variety of sounds, from deep bass to crystal-clear high-pitched notes, and

\footnotetext{
*Correspondence: marie-gabrielle.durier@|sce.ipsl.fr; christine.hatte@lsce. ipsl.fr

${ }^{1}$ Laboratoire des Sciences du Climat et de L'Environnement, UMR 8212 CEA CNRS UVSQ, Université Paris-Saclay, 91191 Gif-sur-Yvette, France Full list of author information is available at the end of the article
}

finger strokes that can be or gentle or violent. This highly esteemed and mainly solo instrument connotes the refinement and sophistication of the literati, the Chinese scholarly elite, along with the practice of poetry, painting, calligraphy and chess [2]. The qin is considered as one the objects that best epitomizes Chinese thought [1].

Beyond the elaborate sound images it produces, the qin is also revered as a refined artwork, whose shape is imbued with a strong symbolic meaning. The different parts of the instrument refer to the dragon, the phoenix, the sky and the earth. The making of a qin corresponds to an ideal such as a concentration of the harmony of nature, the energetic flow (qi), and all the forces of the Universe [1]. The materials selected are therefore invested with deep meaning, such as timber from temples that is impregnated with chanting, or from trees growing near
Springer Open

(c) The Author(s) 2021. Open Access This article is licensed under a Creative Commons Attribution 4.0 International License, which permits use, sharing, adaptation, distribution and reproduction in any medium or format, as long as you give appropriate credit to the original author(s) and the source, provide a link to the Creative Commons licence, and indicate if changes were made. The images or other third party material in this article are included in the article's Creative Commons licence, unless indicated otherwise in a credit line to the material. If material is not included in the article's Creative Commons licence and your intended use is not permitted by statutory regulation or exceeds the permitted use, you will need to obtain permission directly from the copyright holder. To view a copy of this licence, visit http://creativecommons.org/licenses/by/4.0/. The Creative Commons Public Domain Dedication waiver (http://creativeco mmons.org/publicdomain/zero/1.0/) applies to the data made available in this article, unless otherwise stated in a credit line to the data. 
water cascades, or in calm and secluded places, etc. Great value is attributed to the numerous cracks (duanwen) on the surface lacquer layer which are considered as a sign of "antiquity", one of the virtues embodied by the qin $[3,4]$.

The ten-year Cultural Revolution (1966-1976) in China had important consequences on the arts, including on the teaching and practice of qin and listening to this instrument [5]. Like other symbols strongly associated with the elites of the Old Empire, efforts were made to "target for destruction" multi-century qin [6]. Nowadays, modern qin makers, recognized as the heirs of this ancestral tradition, perform their work with the remaining knowledge that survived the cultural compliance policy under Mao Zedong [7]. Considering its long history, its numerous cultural and symbolic associations and its crucial role in the shaping of Chinese culture, the qin-along with its musical repertoire-was included in 2008 in the UNESCO list of Intangible Cultural Heritage of Humanity.

To our knowledge, the qin rediscovered in 2012 in the collections of the Conservatoire National des Arts et Métiers (CNAM, Paris) is the oldest qin known in European museum collections. ${ }^{1}$ In view of the evidence in favour of its authenticity, its value is considerable. Research combining a series of scientific techniques and early written sources remains relatively inaccessible and can only be found in Chinese scientific literature or well-informed Chinese expert circles [8]. Likewise, while the literature on Chinese lacquers is abundant [9-12], few scientific reports are available on the material characterization of early qin lacquers $[8,13]$. However, information related to the making of qin appears in the numerous poems praising the instrument and in ancient treatises that shed light on the origin and use of materials [14].

This article combines visual examination of the instrument by qin experts, material characterization analyses and advanced radiocarbon dating technology in an interdisciplinary framework. We will demonstrate that the scientific investigations on the different parts of the qin from the CNAM collection are consistent with the practices of qin craftsmanship that follow a steady tradition throughout the Qin dynasty, as depicted in the following seventeenth and eighteenth-century written sources: the Qinfang "Twenty Four Flavours of qin" which is an early treatise written c.1641 by Xu Shangying [4] and the Yuguzhai Qinpu "Abiding with Antiquity" written c.1860 by Zhu Fengjie which is a very popular late Qing dynasty quqin handbook [3].

\section{Description of the "Qiulai" qin}

\section{An exceptional Chinese zither in European collections}

The qin under study is a Chinese table zither owned by the Conservatoire National des Arts et Métiers (CNAM, inv. $\left.n^{\circ} 04,224\right)$ and currently on loan to the Musée de la musique since 2015 (inv. $n^{\circ}$ D.04224) (Fig. 1). This qin

\footnotetext{
${ }^{1}$ The MET, New York, keeps a qin that belonged to Prince Lu and dated from 1644.

https://www.metmuseum.org/art/collection/search/503523.
}

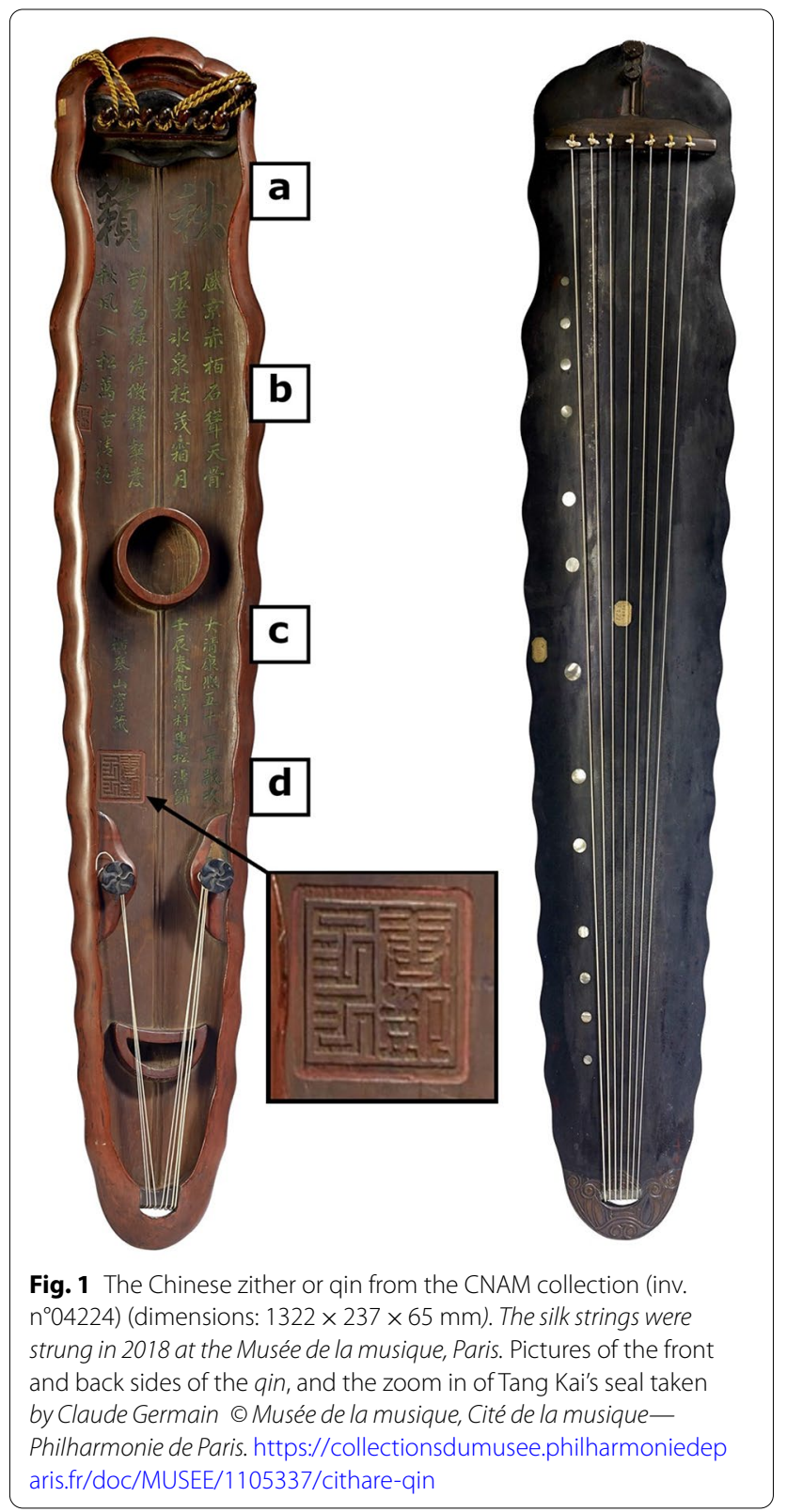

is composed of a soundboard apparently made from a single block of wood, without a bottom, with a system of bridges, peg pool, a nut, two feet to attach seven silk strings, respectively on and under the forehead, the end (tail) and below the soundboard of the qin [15]. Thirteen round studs or emblems (hui) of mother-of-pearl are aligned to mark harmonic positions. The upper and lower parts of the qin symbolize the sky and the earth; two pillars under the soundboard in a circular and a crescent moon shape are called respectively the pillars of "Heaven" and "Earth" (Fig. 1). Visually, the front side is black and the back side is reddish. 
This qin was rediscovered in 2012 during the "récolement" 2 of the musical instruments of the CNAM acoustic collection. Philippe Bruguière, the former Curator of non-European collections at the Musée de la Musique, suspected its old age. The Musical Instrument Museums Online database (MIMO) ${ }^{3}$ was queried to compare this instrument with other qin listed in partner museums, as well as for qin from private collections [16]. The qin has exceptionally rare features with a leaf banana shape known as jiaoye 焦葉 style and the absence of a bottom. The shape and the carved date situate its manufacturing period during the 17 th or eighteenth century in China. For comparison, the "Gumeihua" qin with a similar shape in China (Forbidden City) was made during the Ming 明 dynasty (1368-1644) and once belonged to the collection of the Emperor Qianlong 乾隆 (1735-1796) [17]. The rediscovered qin is assumed to be one of the oldest qin kept in European museum collections.

Despite previous studies based on the CNAM archives and inventories, its provenance remains mysterious. The CNAM was created in 1794 following decrees issued during the French Revolution to promote national industry. The researchers of the CNAM gathered the following clues [18]:

- The presence of musical instruments is attested since 1814 at the CNAM with the installation of the early "Cabinet de physique de M. Charles" who was elected as a physicist to the Académie des Sciences in 1785 [19].

- The qin $\mathrm{n}^{\circ} 4224$ is clearly mentioned in the inventories edited in 1849 at the Conservatoire ${ }^{4}$ for the creation of the acoustics gallery in 1851-1852.

- Objects with inventory numbers around 4000 were presumably kept at the Académie des Sciences prior to their transfer to the Conservatoire. ${ }^{5}$ The Académie des Sciences was initially created in 1666 as an informal scholarly circle and kept collections of objects for scientific studies and education. Some objects were taken from these collections to complete the collection of the Conservatoire after the French Revolution.

\footnotetext{
${ }^{2}$ An operation to check the presence of documents and objects in the collections of French national museums updated every ten years.

3 MIMO: Musical Instrument Museums Online-http://www.mimo-inter national.com/MIMO/ (accessed: 21/05/03).

4 A figure of the qin is also briefly presented in the official catalog of the Conservatoire collections from 1905: "King" (Fig. 12 no. 4224) Chinese stringed instrument". The term "Conservatoire" is used here to avoid anachronisms due to the numerous changes of name of the CNAM over time.

5 The objects with inventory numbers from 3570 to 4541 do not have a well-documented provenance. They likely came from the Académie des sciences in Paris, but they may also have come from property seized by revolutionaries from nobles who fled France during the French Revolution, or from lootings during Napoleon's conquests across Europe.
}

\section{Inscriptions and meaning}

The inscriptions engraved on the back side of the qin are reported in Fig. 2. First, they refer to the name of the instrument “Qiulai" 秋籟 meaning "Autumnal resonances" (Fig. 2a). The following inscriptions in carved Manchu reproduce an extract from the famous poem "Qinzan" 琴贊 "In praise of the qin" written by Li Bai 李白 (701-762) (except the first verse and some slight modifications in red (Fig. 2b). The bottom part of the inscriptions includes information on the making of the instrument (Fig. 2c) and Tang Kai's seal (Fig. 2d). Tang Kai 唐凱 was a well-known court zither player and zither maker, as well as a qin collector during the reigns of the Chinese emperors Yonzheng 雍正 (1722-1735) and Qianlong 乾隆 (1735-1796) of the Qing 清 Dynasty (1636-1912) [17]. The inscription Songtao 松濤 "gusts of wind in the pines" refers to the nickname of Tang Kai whose complete hao (i.e. pseudonym) is Longwan cunsou Songtao 龍灣村兒松濤 "the so-called old man of the gusting wind in the pines of Longwan". 6 According to the carved inscriptions (Fig. 2c), the making of the qin is dated 1712, which is consistent with the period of activity of Tang Kai. This maker is known to have owned seven ancient qin 古琴 with similar inscriptions and the same seal as the "Qiulai" qin [20]. However, no early written sources mentioned this "Qiulai" 秋籟qin in his collection, even though the name is common for a musical instrument.

\section{Material composition \\ Wood}

The monoxylous wooden body of the "Qiulai" qin is made of the light porous brown resinous species from the Taxus genus belonging to the Taxaceae family. ${ }^{7}$ The forehead of the qin has been carved in hardwood teak, i.e. Tectona grandis from the Lamiaceae family.

Based on the legacy of the surviving written sources and the practices of modern makers, the commonly mentioned wood species for each part of the instrument are as follows $[14]^{8}$ :

i. For the soundboard: tong 桐 tree, wutong 梧桐, paotong 泡桐, qingtong 青桐, etc.; or spruce 雲杉, or cedar shan 杉 or "cloud fir wood" yunshan 雲杉.

\footnotetext{
${ }^{6}$ Personal communication from François Picard (2013/12/17).

7 Botanical identifications performed by Victoria Asensi (৫Xylodata), 2015/01/14, and by Catherine Gill (Laboratoire de Paléobotanique, Université Pierre et Marie Curie, Paris), 2015/04/14, based on micrographs taken by Anne Houssay with an optical microscope Zeiss Axio Scope.A1 Vario and by comparing to a database of Chinese forests (http://www2.ffpri. affrc.go.jp/fdb/esawoodq/wood.html). Reports available at the Musée de la musique.

8 Wood species listed in a personal communication from Lucie Rault (2021/03/29).
} 


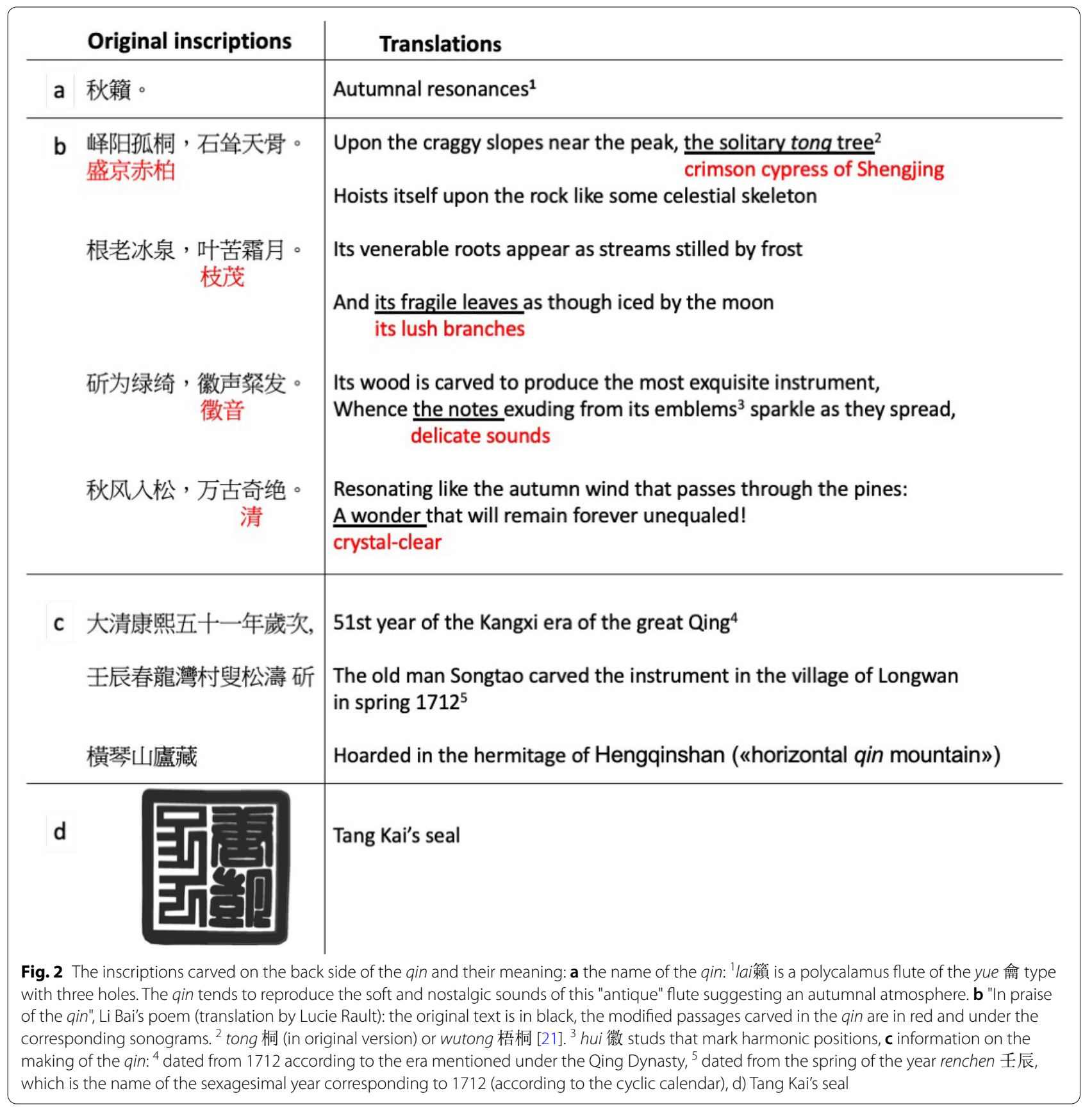

ii. For the back side: $z i$ 梓 or $q i u$ 楸 trees, i.e. catalpa; or $q i$ 漆tree i.e. Toxicodendron vernicifluum or lacquer tree.

iii. For the foot: $w u$ 烏 tree, i.e. black ebony.

The Taxus wood is not a conventional wood used in the making of qin since the Chinese literature and tradition mainly cite the tong 桐 tree as the foremost wood used $[3,14,22]$.

\section{Coating}

The wooden body of the "Qiulai" qin is completely covered with black and red coatings, providing a strong impression of the homogeneity and cohesion sought by the qin maker [4]. We will choose the term "lacquer" in the following due to the traditional use of raw tree lacquer as organic binder (Additional file 1: Fig. S1). Traditionally, the lacquer ash layer huitai 灰胎 is applied on the wood support as the preparation layer. It is usually 


\section{a}
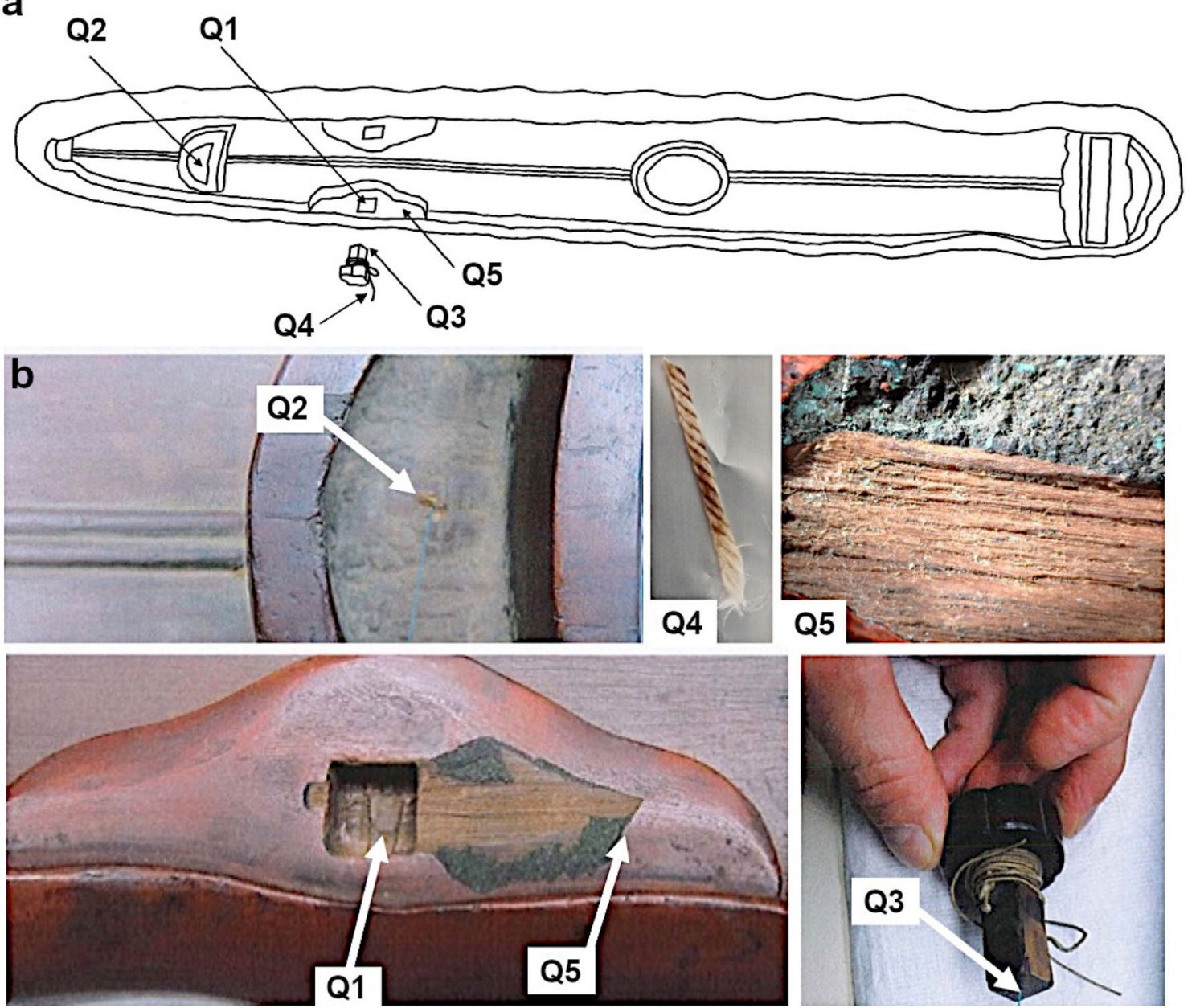

Fig. 3 Location of the samples on the gin: a schematic view of the gin and location of the five samples, $\mathbf{b}$ pictures of the sampling location by Stéphane Vaiedelich @ Musée de la musique, Cité de la musique_Philharmonie de Paris

described as a miscellaneous mixture of Toxicodendron vernicifluum lacquer, deer bone powder, deer antler, pig's blood, brick, lime, mother-of-pearl, gypsum, gold, silver, jade, agate, coral, shells, etc. The lacquer was applied in several layers to give the finishing veneer. Great value is attributed to ancient qin whose lacquer layer is marked by numerous cracks named duanwen 斷紋. Surprisingly, the lacquered surface of the "Qiulai" qin has no cracks (duanwen).

\section{Silk}

The strings that were found knotted around the feet and the bridge prior to their changes in 2018 are made of silk (Fig. 3). The silk came traditionally from insect cocoons named jiacan or domestic silkworm in Chinese and the species used is Bombyx mori. A coating of dirt, glue or wax on the surface of the strings is visible, ranging from off-white to brown-black. Early recipes suggest the use of fish glue, wax or boiled rice for the impregnation of boiled silk strings that helps hold the fibers together and influences the sound [3].

\section{Methods}

Sampling

Micro-sampling was performed on the qin for radiocarbon dating. The size of the samples ranged from 0.2 to $1.4 \mathrm{mg}$ on discrete parts of the back of the body of the qin in order to respect the aesthetic integrity of the object (Fig. 3, Table 1). 
Table 1. Description of samples Q1 to Q5.

\begin{tabular}{lll}
\hline Sample & Location & Material composition \\
\hline Q1 & Bottom of the foot pool & Wood \\
Q2 & Pillar - back of the qin & Wood \\
Q3 & Foot & Wood \\
Q4 & String & Silk \\
Q5 & Coating crack near the foot pool & Coating stratigraphy
\end{tabular}

\section{Material characterization analyses Optical and digital microscopy}

First, the stratigraphy of the lacquers was observed in-situ under visible (VIS), infrared (IR) and ultraviolet (UV) rays using VIS/IR/UV imaging on a Dino-Lite with DinoCapture 2.0 software. Then, a chip of the coating, which comprises the complete stratigraphy from the surface to the wood support, was investigated using light microscopy (Zeiss Axio Scope.A1 Vario) and digital microscopy (3D Keyence-VHX).

\section{$X$-ray fluorescence}

A preliminary investigation was done using X-ray fluorescence spectrometry (XRF) Jetstream M6 from Bruker with a rhodium anode in the X-ray tube at $50 \mathrm{kV}$ and $200 \mu \mathrm{A}$ with a $100 \mu \mathrm{m}$-thick beryllium window. The beam diameter was $450 \mu \mathrm{m}$. The target was placed horizontally at a working distance of $2 \mathrm{~mm}$. The spectra recording time was $200 \mathrm{~s}$, with a maximum count rate of $96 \mathrm{kcps}$. Data were processed with the Esprit software developed by Bruker [23].

\section{MEB-EDS}

The coating sample was embedded in a polyester resin ESCIL-SODY 33, pre-polished with $\mathrm{SiC}$ papers, to obtain a transversal section. Analyses were then performed using Scanning Electron Microscopy with Energy Dispersive X-ray spectroscopy (SEM-EDS) with the JEOL-JSM IT 300 instrument (mode 'HighVacuum', $\mathrm{WD}=10 \mathrm{~mm}$, an energy beam of $20 \mathrm{keV}$, mode BEDC) and an X-ray microanalyzer X-MaxN (Oxford). The results were processed with Aztec software (Oxford).

\section{Raman}

Two different Raman instruments were used. The microspectroscope Raman confocal INVIA Renishaw with a laser source of $532 \mathrm{~nm}$ was used for the black layer of the transversal section of the coating (see "General description of the lacquer layers"). The microspectroscope Raman with a laser source of $785 \mathrm{~nm}$ from BWTek was
Table 2 Description of the sub-samples Q5-1 to Q5-3

\begin{tabular}{|c|c|c|}
\hline Sub-sample & Location & Description of the layers \\
\hline Q5-1 & $\begin{array}{l}\text { Coating crack near the foot } \\
\text { pool }\end{array}$ & $\begin{array}{l}\text { Wood under the black } \\
\text { lacquer }\end{array}$ \\
\hline Q5-2 & $\begin{array}{l}\text { Coating crack near the foot } \\
\text { pool }\end{array}$ & Black lacquer \\
\hline Q5-3 & $\begin{array}{l}\text { Coating around the foot } \\
\text { pool }\end{array}$ & Reddish lacquer \\
\hline
\end{tabular}

used for the red layer of the transversal section of the coating (see "General description of the lacquer layers"). The systems were equipped with an optical microscope (confocal mode, focus $\times 50$ ).

\section{${ }^{14} \mathrm{C}$ analyses \\ Sub-sampling of the coating}

Q1, Q2, Q3 and Q4, were sampled using a cleaned chisel (Fig. 3). The multi-layer lacquer sample Q5 (see "General description of the lacquer layers") required a more elaborate mechanical treatment using microchisels $(0.125 \mathrm{~mm}$, $0.25 \mathrm{~mm}$ and $0.5 \mathrm{~mm}$ ) in order to produce separate ${ }^{14} \mathrm{C}$ measurements on: (1) the wooden support, (2) the black preparation layer and (3) the reddish finishing lacquer (Table 2). Solvents, commonly used by restorers to separate layers, were excluded because they induce carbon contamination. The black lacquer sub-sample Q5-2 was isolated from the wooden sub-sample Q5-1 using a microchisel on sample Q5 under binocular microscope (Table 2). The reddish lacquer layer sub-sample Q5-3 was collected in-situ using microchisels under binocular microscope after removal of a light brown film of dust by scraping with a microchisel (Table 2).

\subsubsection{Chemical pretreatment for ${ }^{14} \mathrm{C}$ dating}

The wooden and silk samples were treated with the classical AAA chemical protocol suitable for wood and charcoal [24] as follows: (i) $\mathrm{HCl} 0.5 \mathrm{M}$ (room temperature) and rinsing with ultrapure water until $\mathrm{pH}=5$, (ii) $\mathrm{NaOH}$ $0.1 \mathrm{M}$ (room temperature) and hot rinsing $\left(80^{\circ} \mathrm{C}\right)$ until $\mathrm{pH}=5$, and (iii) $\mathrm{HCl} 0.5 \mathrm{M}$ (room temperature) rinsing until $\mathrm{pH}=5$. As dust was expected to be the potential lacquer contamination, Q5-2 and Q5-3 underwent acid treatment with $\mathrm{HCl} 0.5 \mathrm{M}$, at ambient temperature and rinsing until $\mathrm{pH}=5$.

Chemical glasses and protective aluminium foils were previously baked out at $450{ }^{\circ} \mathrm{C}$ during $6 \mathrm{~h}$, making them carbon-free. All chemicals were of ultrapure quality, and water was ultrapure (MilliQ grade).

To control the impact of chemical treatment and of the combustion, we also ran in-house "blank" (AfSud, a $70 \mathrm{kyr}$ charcoal from Border Cave, South Africa) and 

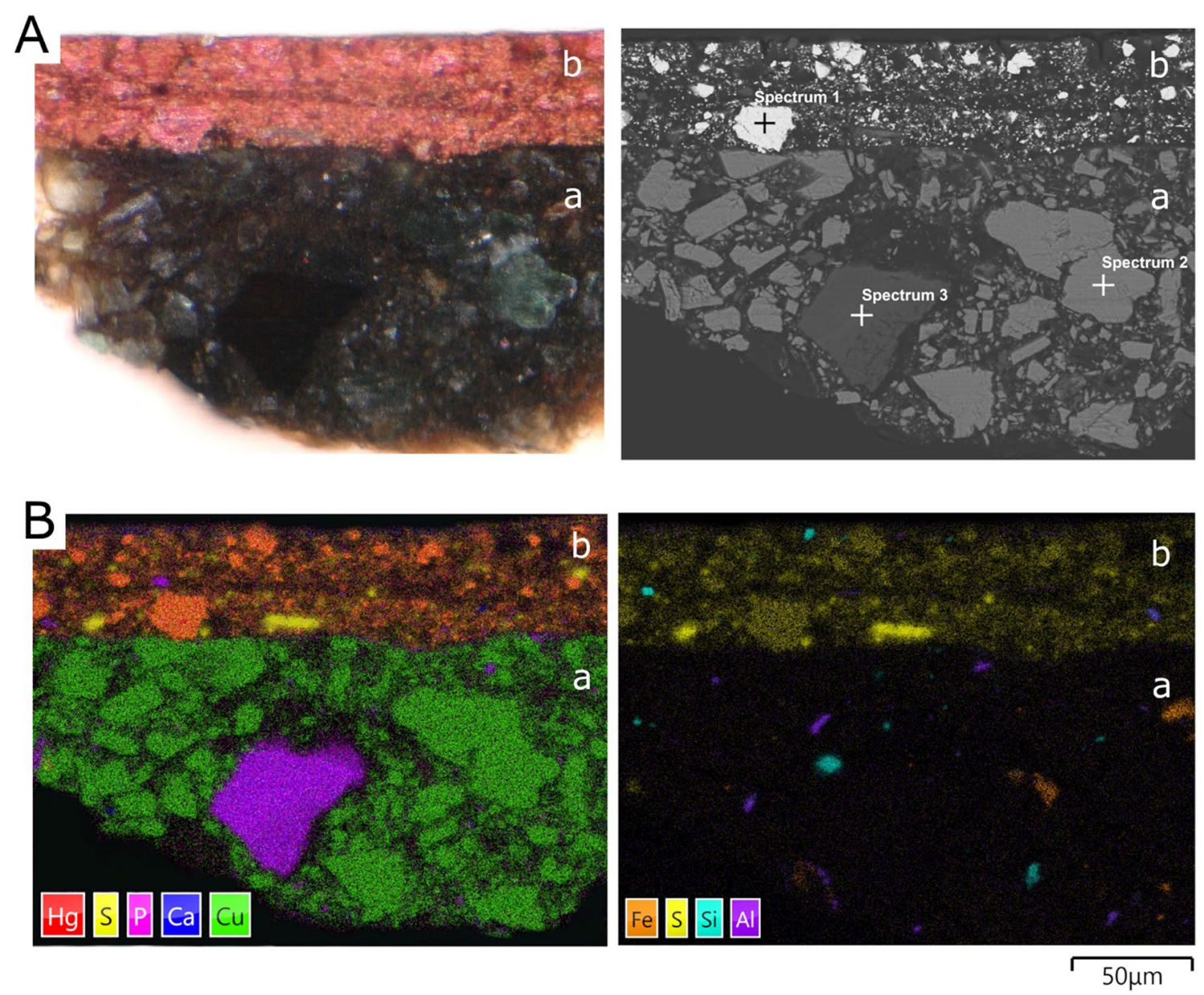

Fig. 4 A (From the left to the right) Image taken by optical microscopy of the two successive layers of the coating sampled on the back side of the gin. SEM image of the transversal section of the coating of the gin; $\mathbf{B}$ (from the left to the right) cartography EDS with the distribution of the main elements in the two lacquer layers of the transversal section. Cartography EDS with the distribution of the minor elements

international standards (wood-SIRI G at $378 \pm 39 \mathrm{BP}$ [25]).

\section{$\mathrm{CO}_{2}$ conversion and physical measurement}

The mass spectrometer ECHoMICADAS was used to measure the ${ }^{14} \mathrm{C}$ activity of each sample [26, 27]. All the samples (from 40 to $160 \mu \mathrm{gC}$ ) were directly injected into an elemental analyser (EA) coupled with the MICADAS gas source through the gas ion source interface (GIS) [28]. The red lacquer sample Q5-3 was an exception and was injected as a gas into the MICADAS gas source through the GIS by tube cracking [29]. $\mathrm{CO}_{2}$ was obtained off-line by combustion under pure $\mathrm{O}_{2}$.

Ages were obtained from ${ }^{14} \mathrm{C}$ measurements using Bats software by comparing ${ }^{14} \mathrm{C} /{ }^{12} \mathrm{C}$ ratios with OXII standards [30]. Most of the samples provided several measurements, but results were statistically combined.
The mean age of the sample then derives from the mean of the individual measurements, which pass the $\mathrm{Chi}^{2}$ test, and is associated to the maximum between the $\mathrm{Chi}^{2}$ reduced error and the standard deviation between the median of the individual measurements. Results are expressed in $\mathrm{F}^{14} \mathrm{C}$ as recommended by Reimer et al. [31] and provided as ${ }^{14} \mathrm{C}$ ages (BP) following Stuiver and Polach's convention [32]. Probability distributions of calibrated ${ }^{14} \mathrm{C}$ ages were generated using $\mathrm{OxCal}$ v4.3.2 [33] based on the IntCal20 calibration curve [34].

\section{Results}

Material characterization

\section{General description of the lacquer layers}

The optical microscopy revealed that the lacquer on the back side of the qin comprises two successive layers: (a) a heterogeneous black layer of around $1 \mathrm{~mm}$ with greenish 
grains applied on the wooden support, (b) a homogeneous reddish surface layer of $35 \mu \mathrm{m}$ lightly covered with a dust deposit (Fig. 4A). According to measurements using $\mathrm{XRF}$, the two layers comprise mainly iron and copper inorganic elements.

\section{The black lacquer}

This layer is black under visible (VIS) and infrared (IR) rays using VIS/IR/UV imaging. Hence, it contains a black pigment absorbing VIS and IR rays, which cannot be iron oxide since it reflects IR rays. We deduced that the pigment is most likely a carbon black: soot, charcoal, stone black, ivory black, vine black or bone black. Respectively using SEM-EDS and Raman spectroscopy, the matrix was identified as being mainly constituted of a filler made of bone black $\left(\mathrm{Ca}_{3}\left(\mathrm{PO}_{4}\right)_{2}\right)$ with coarse-grained malachite $\left(\mathrm{CuCO}_{3}(\mathrm{OH})_{2}\right)$ (Fig. 4B). SEM-EDS analyses also detected silica $\mathrm{SiO}_{2}$, ochres $\left(\mathrm{FeOOH}, \mathrm{Fe}_{2} \mathrm{O}_{3}\right)$ with potassium and magnesium aluminosilicates (Fig. 4B).

\section{The red finishing lacquer}

This layer is red under visible (VIS) and slightly reflective under infrared (IR) rays using VIS/IR/UV imaging. Since XRF analyses applied on the sample Q5 mainly detected $\mathrm{Cu}$ and $\mathrm{Fe}$, we first surmised that the red pigment could be an iron oxide. However, using SEM-EDS and Raman spectroscopy (Figs. 4, 5, 6), the red layer was identified as being mainly constituted of a mercury sulfide $(\mathrm{HgS})$ most likely from the mineral named cinnabar accompanied by sparse particles of pure sulphur (S) (Fig. 4B).

\section{${ }^{14} \mathrm{C}$ dating results}

The sample Q5-2 on the ash lacquer was thick enough to perform four measurements using radiocarbon dating (Additional file 1: Table S1, Fig. 7a). The heterogeneity of these measurements with a weak $\mathrm{A}_{\text {comb }}$ of $5.4 \%$ is consistent with the composition of the lacquer ash layer as a mixture of several solids. The ${ }^{14} \mathrm{C}$ dating mean value obtained [69AD-245AD] is incompatible with the historical information gathered on the "Qiulai" qin.

The wooden samples Q1, Q2, Q3 and Q5-1 yielded similar ${ }^{14} \mathrm{C}$ results. The combination of the results using the "combine" option of Bayesian modelling [33] gave a high agreement index $\mathrm{A}_{\text {comb }}=114.1 \%$. It can be concluded that the wood pieces chosen for the manufacturing of the qin are contemporary. The tree or trees used grew and were cut during the [1458AD-1528AD] or [1552AD-1634AD] intervals (Additional file 1: Table S1, Fig. 7b).

The silk string sample Q4 and the red lacquer sample Q5-3 present similar ${ }^{14} \mathrm{C}$ results (Additional file 1: Table S1). The combination of these measurements, acknowledged by a high $\mathrm{A}_{\text {comb }}$ value of $110.9 \%$, highlighted that the silk strings and the red lacquer are contemporaneous, which might provide the last period of lacquering and changing of the strings on the qin. Considering that the presence of the qin in the CNAM collections is attested since 1849 (terminus ante quem in the Bayesian analysis), this probable last maintenance in playable condition might be included in the following intervals: [1659AD-1699AD] (25.0\%), [1721AD1814AD] (66.6\%) or [1834AD-1848AD] (3.8\%) (Fig. 7c).

\section{Discussion}

\section{Characterization of the wooden body}

The radiocarbon results are consistent with a traditional practice of reusing a symbolic wood when making a qin, as explained in "Abiding with Antiquity", c.1860 [3]. The radiocarbon dating results provide a significant hiatus, that could reach several centuries, between the dating of the wood in the [1458-1528] or [1552-1634] intervals and the dating of the silk string and red finishing lacquer (Fig. 7). The hiatus is relevant to the Chinese tradition which symbolically associates the material quality of "a very old tong wood" with the quality of the sound. This virtue of "antiquity" is cited in the "Twenty-Four Flavours of qin", ca. 1641, and detailed in the introduction by Goormaghtigh, as part of the aesthetic canons [4]. Such a music appreciation is still controversially present in the modern practice of carving qin in a wood that has been stored for more than a hundred years [36]. However, the storage of wood through several generations of qin makers is not attested in the past.

The dating hiatus between the wood on the one hand and the red lacquer and string on the other cannot be due to the sun-drying of a multi-century old tree trunk. The wood used to make the qin should be porous, light, even and smooth without the knots or distended and twisted fibers caused by the influence of the sun or the wind on the growth of the wood, as mentioned in early written sources. Therefore, secondary branches are preferentially selected according to an appropriate age and height [22]. The Tang period poems $(618-690,705-907)$ studied by You [14] confirm the preference for secondary branches rather than the trunk, except in the case of a tree less than a decade old.

"As for the material that should be used, it should be from younger branches; that is, branches that are close to the top of the trunk. If the tong is not old, then its young branches will certainly not be big. Choose wood far away from the ground, with the top blown by wind and dried by sun. It should 

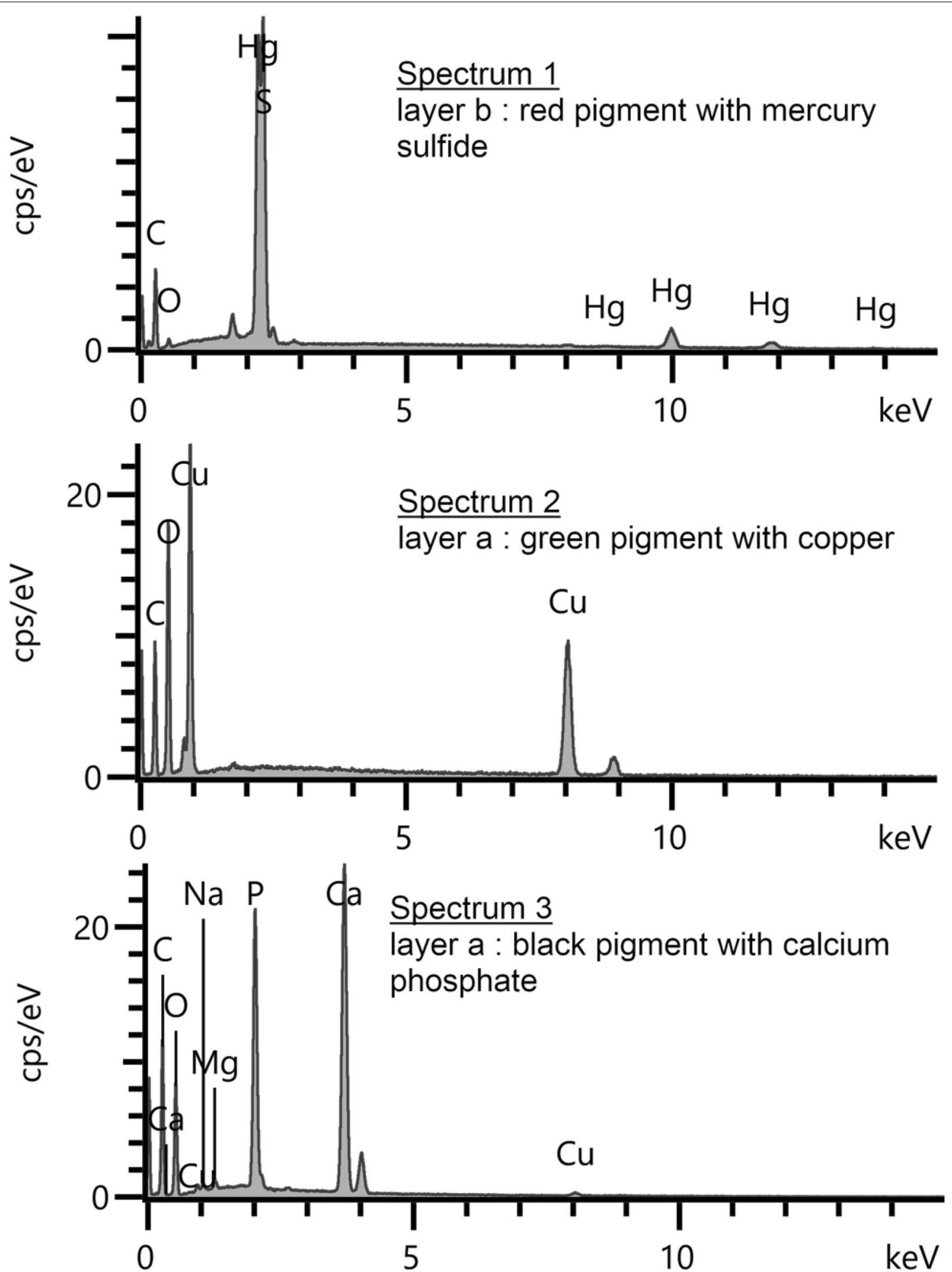

Fig. 5 The upper spectrum correspond to the homogeneous red lacquer (b), and the following spectra to the heterogeneous black layer (a) and were obtained using SEM-EDS 

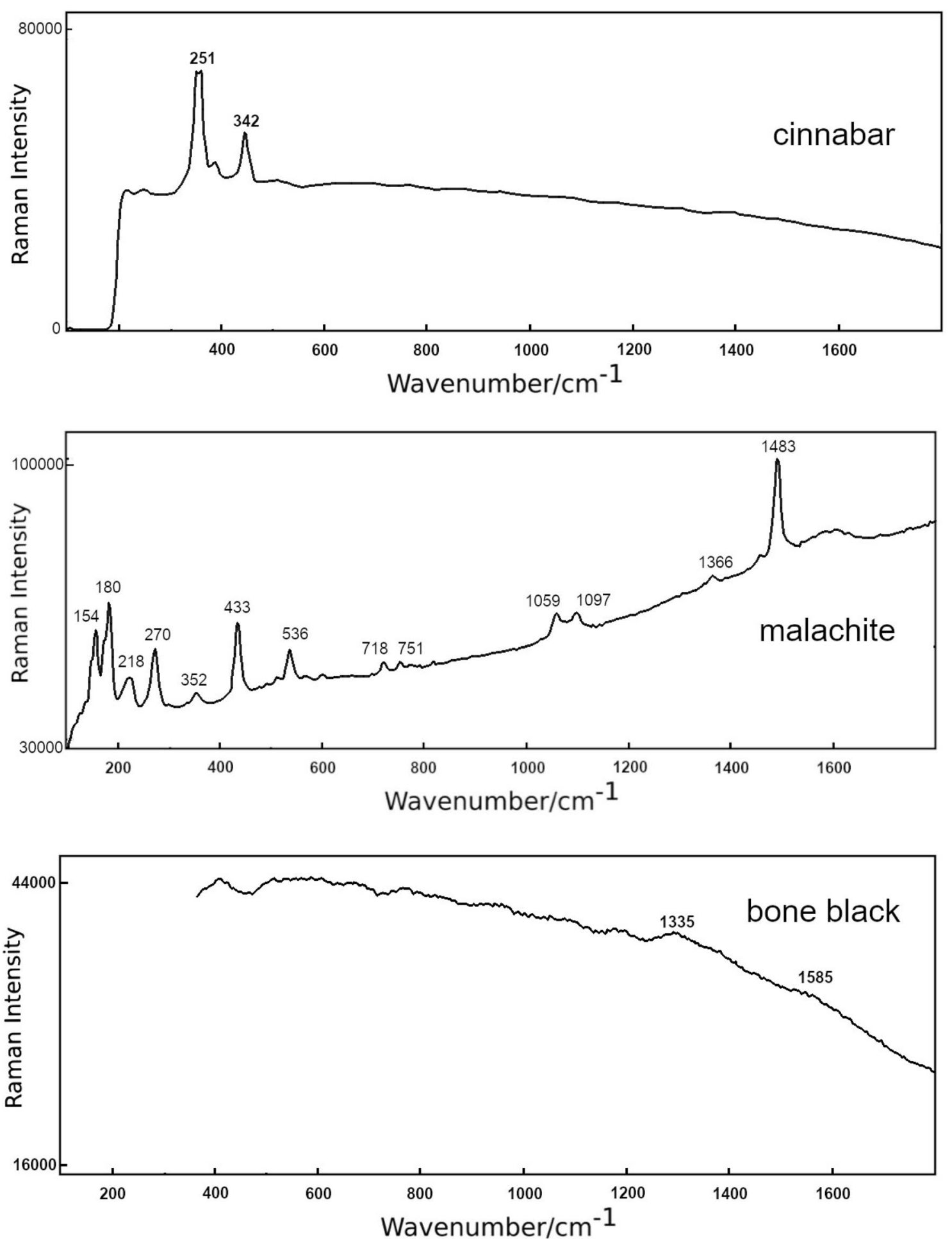

Fig. 6 (From the top to the bottom) Raman spectra for the identification of mineral pigments in the finishing lacquer (b) with some red grains showing the presence of cinnabar, and in the black lacquer (a) with several coarse green grains showing the presence of malachite, and with grains of bone black [35] 


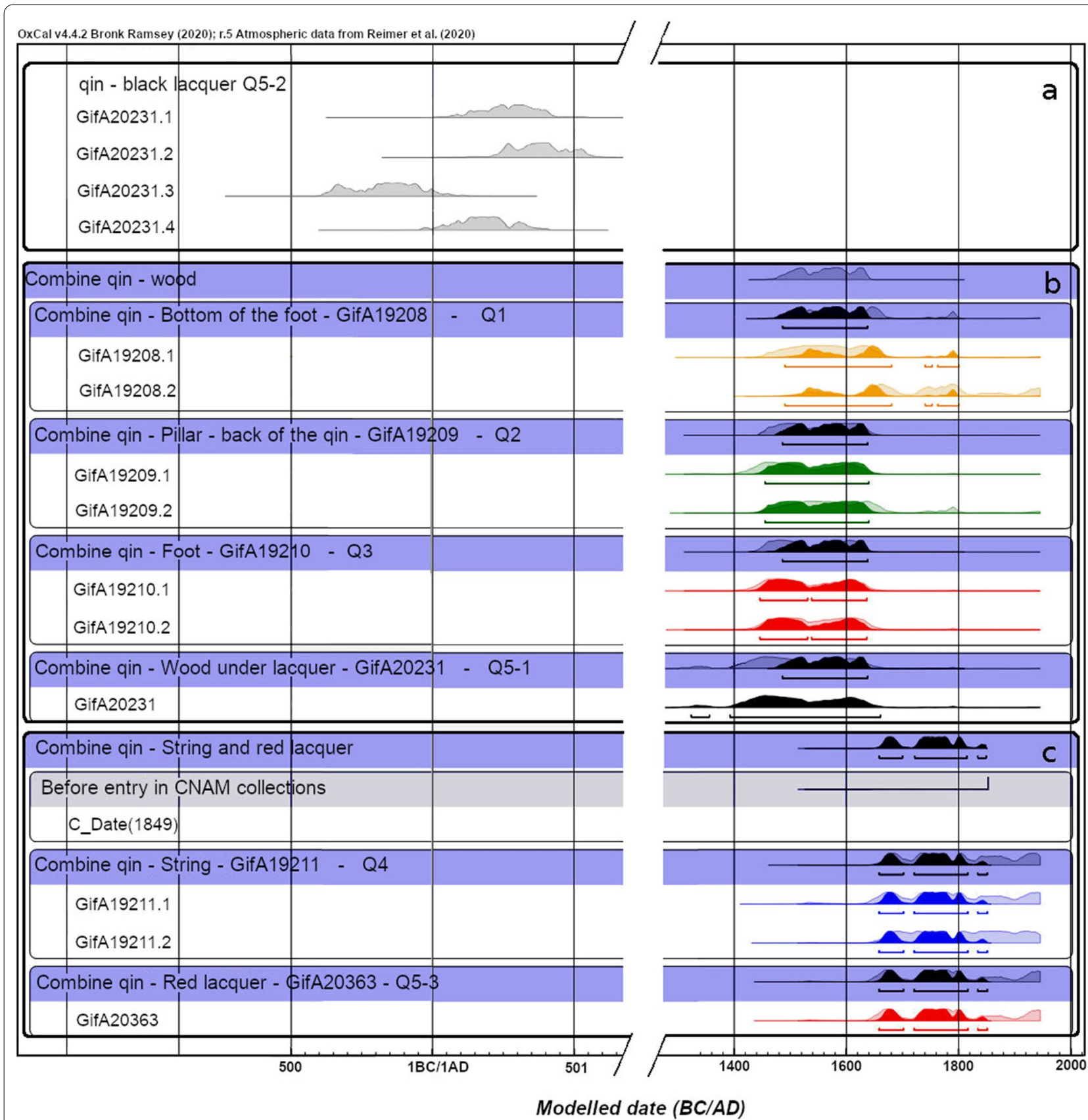

Fig. 7 Calibrated ${ }^{14} \mathrm{C}$ ages of the "Qiulai" qin. The probability distribution diagrams of: a sub-samples of the black lacquer Q5-2; $\mathbf{b}$ wooden samples of the back side of the foot Q1, the pillar Q2, the foot Q3 and the wood support under the lacquer Q5-1 with their respective Bayesian modeling combination in black, and the upper diagram in blue of the combination of all wooden parts; c sub-sample of the upper lacquer in red Q5-3 and sub-samples of the silk string in blue Q4 with their respective Bayesian modeling combination in black, and the upper diagram in black of the combination of the red lacquer and the silk string parts taking into account the event of the entry of the gin in the CNAM collection prior to 1849 
be moistened by frost and dew with plenty of pure air. Furthermore, it is good if the material is facing southeast, (because) "the Great Brightness (the sun) is born in the east". ${ }^{\prime}$

The Book of Odes ${ }^{10}$ states: "The wutong grows there on those slopes and faces the sun"11 [3]

The interpretation of the ${ }^{14} \mathrm{C}$ results as due to the reuse of wood is reinforced by the fact that the "Qiulai" qin is not made from a conventional tong species, but from a porous resinous wood from the Taxus family. Considering that the changes in Li Bai's poem carved on the back side are a subtle and skilful adaptation to this particular qin, the replacement of the sinogram tong 桐 by bai 柏 for resinous woods of cedar or cypress may be linked to this manufacturing choice. Other wood species than tong tree can be used, especially old building timbers:

"As for good quality in old materials, (...) one cannot be certain that it will be tong wood. Some other kinds of wood are also all right. The wood is useable as long as it is light and porous, crisp and smooth. (...) As for beams, pillars, and router rafters, the ancients used tong for some of these. But it has to have survived for a couple of hundred years. If at an old monastery or temple on a high precipice or cliff, or by a waterfall, or stream shore in high, spacious and quiet regions, absolutely cut off from the cacophony of the everyday world, there one can find good material for the qin. Naturally it will have a special sound. "[3]

As a testimony of this practice during the nineteenth

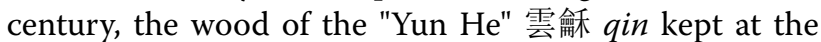
Musical Instruments Museum, Brussels (Coll. MIM, $\mathrm{n}^{\circ}$ inv. 0760) has been identified as originating from Jing Hui 淨慧寺 Temple in the Guangzhou province (Canton) thanks to ink inscriptions on the back side [37]. This unfulfilled epigraph also indicates that the qin was built by the maker Li Menggeng 李夢庚 whose life is poorly known, but who partly coincides meets the reign of Daoguang 道光帝 (1820-1850). The entry of this qin in the MIM collections is dated between 1881 and 1886 according to the inventories.

The ${ }^{14} \mathrm{C}$ results for the wood of the "Qiulai" qin are consistent with a long tradition in qin making that consists in reusing old wood with a highly symbolic and spiritual

\footnotetext{
${ }^{9}$ Da ming sheng yu dong 大明生於東 Liji 禮記 (Book of Rites), Liqi 禮器 (Instruments of rites, 28, https://ctext.org/liji/li-qi/zh).

10 "wutong sheng yi, yu bi chaoyang 梧桐生矣, 於彼朝陽。" Shijing 詩經, 252 https://kknews.cc/culture/5lly9g3.html.

${ }_{11}$ The Yuguzhai qinpu http://web.cecs.pdx.edu/ jrb/chin/v22/v22.htm\#_ ftnref7.
}

value, whether during the period of activity of Tang Kai or in the early nineteenth century before the recorded presence of the qin in the CNAM collection in 1849.

\section{Composition of the lacquer ash layer}

The radiocarbon dating and material characterization of the "Qiulai" qin lacquer ash layer revealed a mixture of two major solid ingredients, bone black and malachite, consistent with the use of powdered deer antler and crushed stones mentioned in the Qinfang c.1641 and the Yuguzhai Qinpu c.1860 [3, 4]. The lacquer ash layer is located between the wood body and the red lacquer. However, the heterogeneous ${ }^{14} \mathrm{C}$ results on this layer with a mean value of [69AD-245AD] are not compatible with the expected period of the making of the qin. Based on the material analyses, the age obtained might be due to the mixing of carbon from ingredients contemporary with the lacquering of the $\operatorname{qin}\left(\mathrm{F}^{14} \mathrm{C}=0.976 \pm 0.007\right.$, value of the red lacquer) with $20 \%$ of geological carbonates from malachite residues $\left(\mathrm{F}^{14} \mathrm{C}=0\right)$ remaining after acid etching during the chemical pretreatment of the subsample Q5-2.

The detection of carbon and phosphorous in the lacquer ash layer of the "Qiulai" qin does not differentiate deer antler ash from deer or another animal bone ash. Li et al. [13] also reported that the detection of $\mathrm{Ca}_{3}\left(\mathrm{PO}_{4}\right)_{2}$ merely indicates the presence of bone ash regarding the "Yu Quan" qin from the Yuan Dynasty. However, traditional recipes comprising the raw sap of the lacquer tree and the ash of deer antlers lujiao shuang 鹿角霜 are mostly cited [14, 38]. According to the Yuguzhai Qinpu c.1860, "Whenever others put on the powder and lacquer they use a cattle horn comb (...). The powder; that is, deer horn shuang霜, (...) should be ground fine."

The detection of the coarse grains of malachite is suggestive of the qin makers' practice of occasionally adding fragments of metal or stone to the lacquer ash layer in accordance with the symbolism of the carillon and lithophone so as to obtain the ideal acoustic properties, as discussed by Goormaghtigh [4] based on the following citation in the Qinfang c.1641: "The fingers struck the strings as if they drummed metal or stone, without any interference from the neighboring strings. It is in this search for limpidity that one goes beyond all sounds". Chang [39] mentioned that the highly estimated lacquer of qin made in the Tang Dynasty (618-690, 705-907) corresponded to the Asian lacquer technology consisting in adding scraps of metallic or stone fillers. A mixture, commonly named "eight precious ash" lacquer baobaohui 八寶灰漆 ${ }^{12}$ by qin makers, is made of fragments of gold, copper, bronze, porcelain, silver, mother-of-pearl, malachite, pearl, jade, agate, coral or seashells [8].

\footnotetext{
${ }^{12}$ http://www.silkqin.com/03qobj/strings/shuchee1.htm.
} 
Powdered deer antler and crushed stones are not ingredients only used for qin lacquers but can be found in Asian lacquers of other objects [40]. For example, a lacquered tray from the Ming period (1368-1644) presents surface "snake-belly cracks" as for qin from the same period, which could be due to the use of similar compounds such as powdered deer antler, bone, horn, ash, sandstone, or ceramics [41]. Our results are consistent with the traditional composition of the lacquer ash layer of qin; however, due to the long tradition spread over several dynasties, a more accurate attribution is not possible.

\section{The silk string and the red lacquer dating}

The analyses revealed that the remaining silk string and the red lacquer are contemporaneous, meaning that the last lacquering and maintenance in playable condition occurred in China during the Qing dynasty (1644-1912) since the radiocarbon dating yielded the [1659-1699], [1721-1814] or [1834-1848] intervals. According to our investigations, three hypotheses are currently available for the attribution of the period when the "Quilai" qin that entered the CNAM collection before 1849 was built: (i) it was collected, dated and signed by Tang Kai in 1712, (ii) it was made by Tang Kai in 1712, or (iii) it is a wellinformed late eighteenth-nineteenth century copy using an old wood carved in China.

The absence of typical cracks duanwen 斷紋 on the lacquer is surprising. Cracks may begin to appear a hundred years after the making, and the shape of the cracks can be used for the relative dating of the qin. Re-lacquering or restoration of the "Qiulai" qin by successive owners can be considered during the [1721-1814] or [1834-1848] intervals, as such practices have already been observed on other ancient qin. ${ }^{13}$ For example, the "Mingfeng" 鳴 鳳 qin is known to have been recut and re-lacquered by Tang Kai [20]. The cracks on the "Xianren you" qin from the Song period (1127-1279) have been wiped out by restoration [42]. However, the cracks are not necessarily proof of antiquity even if this is the reason why Chinese connoisseurs estimate them. Like the "Qiulai" qin, the "Yun He" qin that entered the MIM collection c.1880 presents no surface cracks either.

The "Qiulai" qin shows 18th-century features, and material characterization analyses as well as ${ }^{14} \mathrm{C}$ results are consistent with the traditional practices of the qin makers from this period as described in written sources $[3,4]$. The authenticity of this qin is credible. Indeed, the Qing dynasty period was rich in cultural exchanges

\footnotetext{
${ }^{13}$ For example: Signatures, Inscriptions, and Markings of "Xiangpu's Treasure" Guqin (古琴) translated by Hui Fang, Dept. of Asian Art, December 2014. The Met, 2014 https://www.metmuseum.org/art/collection/search/ 670501 (accessed May 16, 2021).
}

between China and France under the Ancient Regime. French sinophilia during the 18th Century Enlightenment is also well-known under the reign of Qianlong (1735-1796). China's tolerance toward Christianity allowed the establishment of Jesuits whose exchanges with the Académie Royale des Sciences provided information on Chinese techniques of the time. For example, the Jesuit Pierre Nicolas Le Chéron d'Incarville (17061757) sent a memoir to the Académie in 1760 mentioning the use of resin tree and calcined deer bones in black Chinese lacquers [43]. The sending and the studying of qin in the eighteenth century in France is attested. For example, the Jesuit priest Joseph-Marie Amiot (17181793) sent a qin to M. Bertin for his cabinet of curiosities [44], as reported in his correspondence with the Académie des Sciences [45]: “The first is a $\mathrm{Kin}^{14}$ with seven strings, unlike those of today (...). It is made of a single piece of wood".

If the "Qiulai" qin was made by Tang Kai and kept its original lacquer, then it was manufactured in the [16591699] interval, since the ${ }^{14} \mathrm{C}$ dating results on the red lacquer provide intervals that do not include the date of 1712 carved on the back side of the qin. The carving of inscriptions on a qin traditionally took place after the instrument had been made and even played for several years.

\section{Conclusions}

The most significant findings that emerge from this study are that the qin rediscovered in the CNAM collection has exceptional characteristics that are consistent with current knowledge about eighteenth-century qin manufacture. Several aspects might contribute to the testimony of the qin's authenticity: its shape, the carved inscriptions including Tang Kai's seal, the consistent ${ }^{14} \mathrm{C}$ dating of the different materials of the qin, the choice of the wood, the lacquer composition and stratigraphy, while the archival documents and the absence of cracks duanwen 斷紋 provide additional clues testifying that the qin was scarcely played and well-preserved in the French collections prior to 1849 . While interdisciplinary investigations on early Chinese zithers are seldom used, our results were achieved thanks to the combination of material characterization techniques, advanced radiocarbon dating technology and museum expertise confronted with early Qing dynasty written sources. This research project constituted a unique opportunity to study one of the most remarkable qin kept in Europe.

\footnotetext{
${ }^{14}$ Kin is the name given by the Jesuit community under the Ancient Regime to qin.
} 


\section{Supplementary Information}

The online version contains supplementary material available at https://doi. org/10.1186/s40494-021-00563-8.

Additional file 1: Table S1: Conventional, calibrated and modelled ${ }^{14} \mathrm{C}$ ages obtained for the "Qiulai" gin using OxCal4.3.2 [33] based on IntCal20 [34]. Statistical results of Bayesian modelling are shown in the last four columns. Fig. S1. (from the top to the bottom) ATR-IRTF spectra of the finishing lacquer (b) and the black lacquer (a) with a noised signal, especially for the black layer due to the presence of inorganic elements such as copper, gypsum or aluminosilicates. The pics are relevant with lacquer spectra (database IRUG http://irug.org/search-spectral-database) [46]. Data were recorded within the range $4000-500 \mathrm{~cm}^{-1}$ using a spectrometer Nicolet 6700 equipped with a diamond ATR module (SMART endurance) and with the OMNIC software (Thermo Fisher Scientific) [47].

\section{Acknowledgements}

The authors warmly acknowledge Lucie Rault and Benjamin Meunier for translations from Chinese, Didier Brissaud for the Raman spectroscopy analysis, Marie Radepont and Oulfa Behadj for in situ XRF and FTIR analyses, Francois Thil and Nadine Tisnérat-Laborde for their help in physical measurements and validation of ${ }^{14} \mathrm{C}$ data. The authors would also like to thank Philippe Bruguière, Julie Chang, Claire Chantrenne, Simon Debierre, Jing Han and Wang Yuegong for thoughtful indications and suggestions and Lucie Rault and Francois Picard for reviewing this article. Authors are grateful to Elizabeth Rowley for editing the English of the article. Finally, the authors are indebted to two anonymous reviewers whose comments helped to improve the original manuscript.

\section{Authors' contributions}

MGD and SV designed the study with input from CH and AGM. CF was responsible for the loan of the object and agreed with the way the study was conducted. MGD, AGM, SV, CF are responsible for the historical and scientific documentation of the instrument. Radiocarbon and statistical analysis were performed by $\mathrm{CH}$ and MGD. TF prepared cross sections and performed material characterization on samples. TF and WN discussed the results and interpreted them in the context of radiocarbon dating. The global interpretation was the result of a collective thinking of all authors. MGD wrote the manuscript with input from all co-authors. All authors read and approved the final manuscript.

\section{Funding}

This work is part of Ph.D. research funded by the Fondation des Sciences du Patrimoine, and supported by the Musée de la musique (Paris), the Laboratoire des Sciences du Climat et de l'Environnement (Gif-sur-Yvette), the Centre de Recherche sur la Conservation (Paris) and the Université de Versailles-Saint-Quentin-en-Yvelines.

\section{Availability of data and materials}

All data generated or analyzed during this study are included in this published article. Raw data (including spectra) are available upon request from the authors.

\section{Declarations}

\section{Competing interests}

The authors declare that they have no competing interests.

\section{Author details}

${ }^{1}$ Laboratoire des Sciences du Climat et de L'Environnement, UMR 8212 CEA CNRS UVSQ, Université Paris-Saclay, 91191 Gif-sur-Yvette, France. ${ }^{2}$ Centre de Recherche sur la Conservation (CRC), Muséum National d'Histoire Naturelle (MNHN), Ministère de la Culture, CNRS USR 3224, 36 rue Geoffroy-Saint-Hilaire, 75005 Paris, France. ${ }^{3}$ Musée de la Musique, Cité de la Musique - Philharmonie de Paris, 221 avenue Jean Jaurès, 75019 Paris, France. ${ }^{4}$ Curator, Musée de la Musique, Équipe Conservation Recherche, CRC, MNHN, CNRS USR 3224, Ministère de la Culture, 36 Rue Geoffroy-Saint-Hilaire, 75005 Paris, France.

${ }^{5}$ Laboratoire de Recherche des Monuments Historiques (LRMH), 29 rue de
Paris, 77420 Champ-sur-Marne, France. ${ }^{6}$ Curator, Musée des Arts et Métiers (CNAM), 60 rue Réaumur, 75003 Paris, France.

Received: 24 June 2021 Accepted: 13 July 2021

Published online: 24 July 2021

\section{References}

1. Rault L. Musiques de la tradition chinoise. Actes sud. Arles; 2000.

2. Picard F. La musique chinoise. You-Feng. Paris; 2003.

3. Zhu 祝鳳㫮 F. Yuguzhai Qinpu 與古齋琴譜 (Abiding with Antiquity) [Internet]. Fujian, China; 1860. Available from: English translation James Binkley, Abiding with Antiquity, 2006 https://www.lulu.com/content/ 402391 see Yu-Ku-Chai translation http://web.cecs.pdx.edu/ jrb/chin/

4. Goormaghtigh G. L'art du qin. Institut Belge des hautes études chinoises. Bruxelles; 1990.

5. Run MY. Music under Mao, its background and aftermath. Asian Music. 1991;22:97-125.

6. Tsai T-H. From confucianist meditative tool to maoist revolutionary weapon: the seven-stringed Zither (Qin) in the Cultural Revolution. Listening to China's Cultural Revolution Chinese Literature and Culture in the World [Internet]. Clark P, Pang L, Tsai TH. New York: Palgrave Macmillan; 2016. p. 42. https://doi.org/10.1057/9781137463579_3.

7. Luo M. Cultural policy and revolutionary music during China's Cultural Revolution: the case of the Shanghai Symphony Orchestra. Int J Cult Policy. 2016;24:431-50.

8. Wang 王莉 L. Research on the raw lacquer film of "Hu Xiao" Guqin collected in Shaanxi History Museum 陕西历史博物馆藏“虎啸”琴漆膜 研究. Sciences of conservation and archeology 文物保护与考古科学. 2020:32:73-81.

9. Webb M. Lacquer: Technology and Conservation. Oxford: ButterworthHeinemann; 2000.

10. Raffaëlly L, Pons E, Lacoudre N, Bleton J, Vo Duy S, Tchapla A. Caractérisation physico-chimique de laques de Mongolie du ler siècle ap. J.-C. ArcheoSciences Revue d'archéométrie. 2005;69-81.

11. Heginbotham A, Khanjian H, Rivenc R, Schilling M. A procedure for the efficient and simultaneous analysis of Asian and European lacquers in furniture of mixed origin. ICOM Committee for Conservation 15th Triennial Meeting. New Delhi: Allied Publishers; 2008. p. 608-16.

12. Chang 張倚竹 J, Schilling MR. Reconstructing lacquer technology through Chinese classical texts. Stud Conserv. 2016;61:38-44.

13. Li 李澜 L, Hao 郝锌颖 X, Yang 杨燕 Y, Ni 倪芳芳 F. Analysis of the composition, structure and lacquering technique of a Yuan Dynasty Guqin named "Yu Quan" 馆藏元代玉泉古琴结构和鬆漆工艺的科学 研究. Sciences of conservation and archeology 文物保护与考古科学. 2020;32:29-34.

14. You L-Y. Facture et jeu de la cithare chinoise qin sous la dynastie des Tang [Musique et Musicologie]. Paris: Université Paris-Sorbonne; 2017.

15. Penttinen H, Pakarinen J, Välimäki V, Laurson M, Kuuskankare M, Li H, et al. Physical modeling of the guqin - a Chinese string instrument. First Nordic Music Technology Conference (NoMute 2006). Trondheim, Norway; 2006.

16. Bell Y. Gems of ancient Chinese zithers: Shum's collection of antique qin from the last Millenium. Hong Kong: University Museum and Art Gallery; 1998.

17. Wang 王跃工Y. Qianlong shiqi gongting qin shi kao 乾隆时期宫廷琴事 考 On Classical Chinese Qin-Zither (Gu qin) of Emperor Qianlong's Court. Gugong bowuyuan yuankan 故宫博物院院刊 Palace Museum Journal. 2018;196. https://www.dpm.org.cn/journal/246829.html.

18. Reibel L. La collection d'instruments de musique du musée des arts et métiers : récolement, étude et valorisation [Diplôme de Conservateur du Patrimoine]. Musée des Arts et Métiers (CNAM), Paris: Institut National du Patrimoine (INP); 2012.

19. Blondel C-J. Un enfant illustre de Beaugency, le physicien et aéronaute Jacques Charles (1746-1823). Académie d'Orléans. Orléans; 2003. https:// gallica.bnffrf/ark:/12148/bpt6k65454933.

20. Zheng 郑珉中 M. Ji mizu zhenggui de Tang Kai cangqin 记弥足珍贵的 唐凯藏琴 Precious ancient zither collected by Tang Kai. Shoucang jia 收 藏家. 2008;12:73-8.

21. Yim LCH. The Poet-historian Qian Qianyi. Abingdon: Routledge; 2009. 
22. Cai W, Tai H-C. Three millennia of tonewood knowledge in Chinese guqin tradition: science, culture, value, and relevance for Western lutherie. Savart J. 2018;1. http://SavartJournal.org/index.php/sj/article/view/27/ pdf.

23. Radepont M, Échard J-P, Ockermüller M, de la Codre H, Belhadj O. Revealing lost 16th-century royal emblems on two Andrea Amati's violins using XRF scanning. Herit Sci. 2020;8:112.

24. Van Klinken GJ, Hedges REM. Chemistry strategies for organic 14C samples. Radiocarbon. 1998;40:51-6.

25. Scott EM, Naysmith P, Cook GT. Should Archaeologists Care about $14 C$ Intercomparisons? Why? A Summary Report on SIRI. Radiocarbon. 2017;59:1589-96.

26. Synal H-A, Stocker M, Suter M. MICADAS: A new compact radiocarbon AMS system. Nucl Instrum Methods Phys Res Sect B Beam Interact Mater At. 2007;259:7-13.

27. Tisnérat-Laborde N, Thil F, Synal H-A, Cersoy S, Hatté C, Gauthier C, et al. ECHoMICADAS: A new compact AMS system to measuring $14 \mathrm{C}$ for Environment, Climate and Human Sciences. Radiocarbon. Dakar, Senegal; 2015. p. 16-20.

28. Ruff M, Szidat S, Gäggeler HW, Suter M, Synal H-A, Wacker L. Online radiocarbon measurements of small samples using elemental analyzer and MICADAS gas ion source. Nucl Instrum Methods Phys Res Sect B Beam Interact Mater At. 2010;268:790-4.

29. Ruff M, Fahrni S, Gäggeler HW, Hajdas I, Suter M, Synal H-A, et al. On-line radiocarbon measurements of small samples using elemental analyzer and MICADAS gas ion source. Radiocarbon. 2010;52:1645-56.

30. Wacker L, Christl M, Synal H-A. Bats: A new tool for AMS data reduction. Nucl Instrum Methods Phys Res Sect B Beam Interact Mater At. 2010;268:976-9.

31. Reimer PJ, Brown TA, Reimer RW. Discussion; reporting and calibration of post-bomb 14C data. Radiocarbon. 2004:46:1299-304.

32. Stuiver M, Polach HA. Discussion: Reporting of 14C data. Radiocarbon. 1977:1:355-63.

33. Bronk Ramsey C. Bayesian analysis of radiocarbon dates. Radiocarbon. 2009;1:337-60.

34. Reimer PJ, Austin WEN, Bard E, Bayliss A, Blackwell PG, Bronk Ramsey C, et al. The IntCal20 northern hemisphere radiocarbon age calibration curve (0-55 cal kBP). Radiocarbon. 2020;62:725-57.

35. Clark RN, Roush TL. Reflectance spectroscopy: Quantitative analysis techniques for remote sensing applications. J Geophys Res Solid Earth. 1984;89:6329-40.
36. Zeng 曾筊涵 X. Investigating the wood properties of antique musical instruments using IR and solid-state NMR spectroscopy 以紅外線與固 態核磁共振光譜探索古代樂器木材特性. National Taiwan University; 2020 .

37. Li H. Unfulfilled Epigraphy - The qin "Yun $\mathrm{He}$ " and its contriver $\mathrm{Li}$ Menggeng. Chinese instruments and western museums CHIME meeting. Leiden, the Netherlands; 2012.

38. Zheng 郑珉中 M. A collection of my observations: a study of Guqin and others 蒛测偶录集:古琴鉴定及其他. Forbidden City Press. Beijing; 2010;218-24

39. Chang B. Traditional technique of lacquer. Thirty Great Inventions of China. Jueming Hua, Lisheng Feng. Singapore: Springer; 2020. p. 313-42.

40. Liu L, Hao W, Wanxiang L, Decai G, Zhanyun Z. Lacquering craft of Qing Dynasty lacquered wooden coffins excavated from Shanxi, China - A technical study. J Cult Herit. 2016;20:676-81.

41. Watt JCY, Ford BB. East Asian Lacquer: The Florence and Herbert Irving Collection. Metropolitan Museum of Art. New York; 1991.

42. Taipei Chinese Orchestra 台北市立國樂團鴻福美術館, The Chang Foundation Museum 鴻禧美術館. The Ancient Chinese Zither(Qin) 唐元 明百琴展實録. Taiwan; 2020 .

43. Watin J-F. Mémoire sur les vernis à la Chine, Par le père d'Incarville, Jésuite \& correspondant de l'Académie des Sciences. L'art du peintre, doreur, vernisseur, ouvrage utile aux artistes et aux amateurs qui veulent entreprendre de peindre, dorer et vernir toutes sortes de sujets en bâtimens, meubles, bijoux, equipages, etc. Paris; 1773. https://gallica.bnf.fr/ark:/ 12148/bpt6k841821.textelmage

44. Picard F. Joseph-Marie Amiot, jésuite français à Pékin, et cabinet de curiosités de Bertin. Musique Images Instrum Collect Instrum Musique 1ère Partie. 2006:69-86.

45. Amiot J. Mémoire sur la musique des Chinois, tant anciens que modernes. Nyon l'aîné. Paris; 1779.

46. Hao X, Wu H, Zhao Y, Tong T, Li X, Yang C, et al. Analysis on the composition/structure and lacquering techniques of the coffin of Emperor Qianlong Excavated from the Eastern Imperial Tombs. Sci Rep. 2017;7:1-11.

47. Gimat A, Michelin A, Belhadj O, Pellizzi E, Massiani P, Rouchon V. Paper sizing with gelatine: from the macro- to the nano-scale. Cellulose. 2021;28:2419-32.

\section{Publisher's Note}

Springer Nature remains neutral with regard to jurisdictional claims in published maps and institutional affiliations.

\section{Submit your manuscript to a SpringerOpen ${ }^{\circ}$ journal and benefit from:}

- Convenient online submission

- Rigorous peer review

- Open access: articles freely available online

- High visibility within the field

- Retaining the copyright to your article

Submit your next manuscript at $\boldsymbol{\nabla}$ springeropen.com 